الأمية وأثرها على التتمية

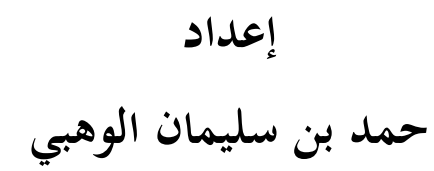

الأستاذ الدكتور

خليل بن ابراهيم السعادات 
التنمية في مفهومها العام هي التغيير المنشود والتطوير الشامل للمجتمع بكل فعالياته وتكويناته، حتى يقوى على اشباع الحاجات الأساسية لأفراده، ويعمل على تحقيق الرفاهية لهم، مما يحسن الإنتاجية والكفاءة.

وقد عملت الدول العربية على السير في ركاب التنمية، أسوة بغيرها من الدول الأخرى التي نالت حظاً أوفر منها في هذا السبيل، يحدوها الأمل العريض في أن تتخلص من طوق التجزئة والتخلف والتبعية التي فرض عليها من قبل الدول الطامعة في مقدراتما وخيراتها (بدران

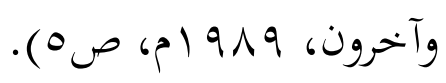
مشكلة البحث: تُشكل الأمية أهم وأخطر المشكلات التي تواجه الدول النامية في الوقت الحاضر باعتبارها مشكلة قومية ذات أبعاد متعددة تنموية، اقتصادية، اجتماعية، سياسية، وحضارية. وتشير معظم الوثائق المعنية بتقدير حجم مشكلة الأمية والجهود التي بذلت في مواجهتها، إلى أن الموقف قد وصل فيها إلى مرحلة من الجمود، بل إنه في تراجع في بعض الأحيان، فخطر الأمية ما زال متفاقماً يقتضي بالضرورة وقفة تاريخية تقع على عاتق الأمة العربية حكومات

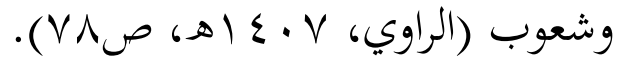
أهمية البحث: تكمن أهمية البحث في النقاط التالية: تقديم نبذة مختصر عن مفاهيم ( محو الأمية، التنمية، التنمية البشرية). تقليم رؤية عامة عن التنمية من حيث مفهومها وابتاهاتا وأثر العولمة عليها. تقديم رؤية عامة عن علاقة التنمية بالتعليم، ورؤية خاصة عن علاقته بمحو الأمية من خلال النظريات التربوية. إضفاء معرفة جديدة إلى حقل تعليم الكبار والاتحاهات الحديثة في محو أُميتهم. 


$$
\text { أهداف البحث: }
$$

- الت التعرف على مفهوم الأمية ومفهوم التنمية. r- التعرف على أثر الأمية على التعليم. ب- ب التعرف على علاقة الأمية بالتنمية. ع - التعرف على النظريات التربوية وعلاقتها بالتنمية. o- - التعرف على المعوقات الخارجية والداخلية للتنمية.

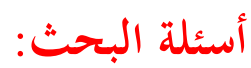
سيحاول البحث في الإجابة على السؤال الرئيسي التالي والأسئلة المتفرعة منه: السؤال الرئيسي: ما هي آثار الأمية على المجتمع وانعكاس ذلك على التنمية البشرية؟ ويتفرع من السؤال الرئيسي الأسئلة الفرعية التالية:

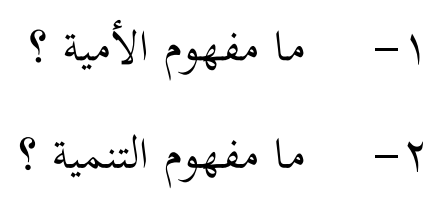
ب- ما علاقة الأمية بالتنمية ؟ ع - - ما هي آثار الأمية على التنمية والتعليم ؟ ه - - عدد النظريات التربوية ذات العلاقة بالتنمية ؟ 7- - ماهي الاتجاهات التربوية المرتبطة بالتنمية ؟ - - - - اذكر المعوقات الخارجية والداخلية للتنمية ؟ منهج البحث: تقيقاً لأهداف البحث وحلاً لمشكلته وإجابةً على أسئلته فإن الباحث سيستخدم المنهج الوصفي في هذا البحث. 


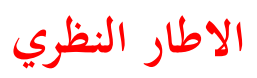

$$
\begin{aligned}
& \text { المحور الأول: الأمية وتأثيرها على التنمية }
\end{aligned}
$$

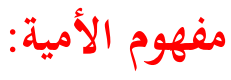
لقد حدد المؤتمر الاقليمي للتخطيط وتنظيم برامج محو الأمية في البلاد العربية المنعقد في الاسكندرية سنة عا9 ام، الأمي بأنه "هو كل من تعدى سن العاشرة ولم يلتحق بالمدرسة، ولم يصل إلى المستوى الوظيفي في القراءة والكتابة باللغة العربية، ويكون الحد الأدلن لهذا المستوى هو عدم القدرة على: قراءة فقرة من صحيفة يومية بفهم وانطلاق. التعبير الكتابي عن فكرة أو اكثر تعبيراً صحيحاً. كتابة قطعة إملاء صحيحة. قراءة الأعداد وكتابتها وإجراء العمليات الحسابية الاساسية. هذا المستوى يمقق للفرد القدرة على الاشتراك اشتراكاً فعالاً في أنشطة القراءة والكتابة التي

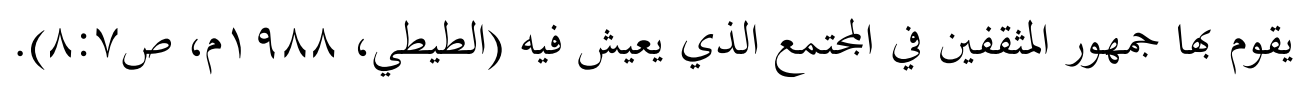
إن المقصود بمحو الأمية بأنواعها المتعددة هو إذهاب أثر الشيء وإزالته. فمعناها لغوياً: إزالة الجهالة. أما اصطلاحاً: فتتوقف على نوع الأمية على النحو التالي: فمحو الأمية الوظيفي: تعني ان التعلم لا يقف عند حد تنمية الافراد بإشباع حاجاتم وتحسين قدراهم، وقد تذهب إلى أبعد من ذلك حيث تعمل للتنمية الشاملة وإشباع حاجات السوق مثل (محو الأمية الصحية، والتربوية، والفنية، وغيرها). محو الأمية الحضاري: يستهدف إحداث تغييرات جذرية في تنمية المحتمع وإيماد مناخ ثقافي ديموقراطي يسمح بتنمية الفرد من خلال تنمية المجتمع في إطار حركة حضارية شاملة. 
محو الأمية الدينية: هي التي لا تقف عند تنمية الافراد بإشباع حاجاتم المعرفية الدينية، وإنما تمد المتعلم بالمهارات الدينية اللازمة لمواءمة التغيرات الاجتماعية من حوله، وبالتالي يتم تحقيق السعادة للفرد في الدنيا والآخرة. محو الأمية الثقافية: تستهدف احداث تغير وتطور في شخصية الدارس الثقافية، وبالتالي تحسين أوضاعه الاجتماعية، وإمداده بالمهارات الضرورية لكي يتكيف في حياته

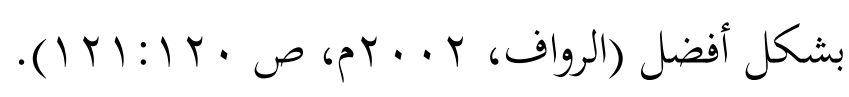
وهناك نوع حديث من أنواع الامية وهو الأمية الإلكترونية: ترتبط الأمية الإلكترونية بالعديد من العناصر التي تساهم في بناء القدرات وخاصة المرتبطة بتقنية المعلومات والمؤثرة في العملية التعليمية، ولقد شهدت السنوات الاخيرة جهوداً متسارعة من قبل الجهات الحكومية والمنظمات غير الحكومية، وشركات القطاع الخاص من أجل تقليم برامج تدريبية لاستخدام تقنية المعلومات، بالإضافة إلى منح

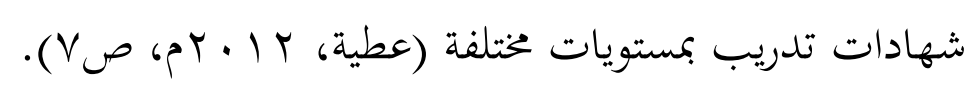

وترتكز برامج محو الأمية الإلكترونية على أربعة أبعاد رئيسية على النحو التالي: ا ـ ـ مهارات التدريب باستخدام تقنية المعلومات. r. التعليم المفتوح والتعليم عن بعد. r. أدوات تطوير المحتوى التعليمي. ع. التصميم الإلكتروني للدروس التعليمية. فإن الجانب العملي التطبيقي لهذه البرامج قد يتلاشى إن لم يكن هناك خلفيات تعليمية وثقافية واجتماعية داعمة وهو الامر المفقود في الدول العربية نظراً لارتفاع نسبة الأمية

$$
\text { الأبجدية المعرفية (عطية، r ا • Yم، صV). }
$$


تبدو أهمية دراسة الأمية لأهما تزودنا بمعرفة تعد من المشاكل المحتدمة، ويبدو أن التعليم والقضاء على الأمية مطلباً عسيراً، فمئات المشروعات القومية والدولية قامت من أجل مكافحة داء الأمية، ومع ذلك فسيل الامية في دول العالم الثالث ما زال جارف، وداؤه مستفحل خحاصة في دول العالم الثالث، ولا سيما الدول العربية. والحق إن الموقف العالمي اليوم لم يعد ينظر إلى الأمية نظرة سهلة، بل دفعته التجارب إلى الإيمان بأن محو الأمية، والقضاء عليها، مسألة في غاية الصعوبة، والتي تبدو خاصة عند التطبيق. وتبدو أهمية محو الامية وتعليم الكبار في اها تستكمل الدور الذي يلعبه التعليم النظامي

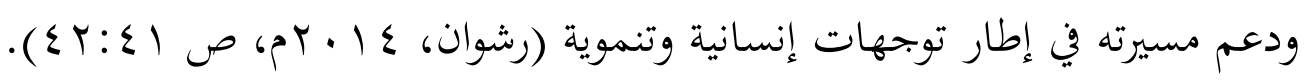
الاتجاهات الحديثة في محو الأمية وتعليم الكبار: إن التطور الذي يشهده العالم في جميع بحالات الحياة ومن بينها بحال التربية، وتعليم الكبار بشكل خاص، والتفجير المعرفي الذي يتميز به هذا العصر، وكذلك انتشار وسائل الاتصال الجماهيري، وسرعة نقل المعلومات بشتى أنواعها كل ذلك استلزم ضرورة بتديد محتوى وأهداف ووسائل تعليم الكبار، وذلك من أجل مواكبة هذه التحديات الجديدة، والمساهمة في تنمية القوى البشرية بمساعدةًا على استيعاب التطورات التكنولوجية، ومن أجل أن

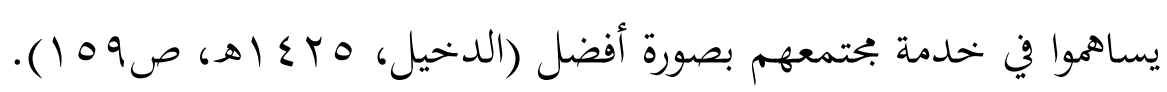
ومن هذه الاتجاهات ما يلي:

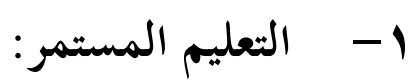

مفهومه: وهو اكساب الفرد المعلومات والابحاهات والقيم والمهارات بالتعلم، حتى يحقق التكيف مع نفسه وبيئته الطبيعية والاجتماعية. 


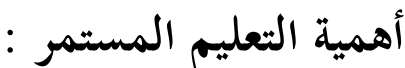

سيولة المعرفة بما يمتاز به العصر الحالي من انفجار للمعلومات الثقافية والمعرفية. تكملة الدور الذي تقوم به المؤسسات التعليمية المختلفة داخل المجتمع.

يشجع المؤسسات التربوية والمهنية المختلفة على الاهتمام بالبحث العلمي (الدخيل،

$$
\begin{aligned}
& .(17): 17.060 \text { ( ) } 17 \text { \% } \\
& \text { r- التعليم الذاتي: }
\end{aligned}
$$

مفهومه: أحد الطرق التعليمية التي يستخدم فيها المتعلم بنفسه كتباً خاصة مبربحة أو آلات

لا يعتمد على اسلوب الحفظ والكم من المعلومات، بل يعتمد على تنمية التفكير الذاتي. زيادة عدد الاميين وصعوبة توفير مقاعد تعليمية لهم بسبب نقص الجوانب المادية والمعلمين، فأصبح التعليم الذاتي حلاً لتعليم هذه من المجتمع (الدخيل، هبك اهـ،

$$
\begin{aligned}
& \text { ص صזr). } \\
& \text { ب- التعليم عن بُعد: }
\end{aligned}
$$

مفهومه: يشتمل على جميع الطرق الدراسية في كل المستويات التعليمية التي لا تخضع

$$
\begin{aligned}
& \text { لإشراف مباشر أو مستمر من قبل المعلم. } \\
& \text { خصائص التعليم عن بعد: }
\end{aligned}
$$

يحقق التعليم عن بعد الاتصال المزدوج بين الطالب والمؤسسة التعليمية. يطبق التعليم عن بعد مختلف نظريات التعلم والاساليب المختلفة لطرق التدريس. تعد التغذية الراجعة جزء اساسي من نظام التعليم عن بعد لتحقيق الفاعلية

$$
\text { والتطوير(الدخيل، 0بع (هـ، ص } 170 \text { (:77 (1). }
$$




$$
\text { ع - التعليم بالمراسلة: هو أقدم أشكال التعليم عن بعد، }
$$

مفهومه: عبارة عن طريقة تعليمية يتحمل المدرس فيها مسئولية توصيل العلم والمهارة المى طالب لا يتلقى العلم شفوياً بل يدرس في مكان ووقت تحدده ظروفه الشخصية. التعليم بالمراسلة يستند الى جانبين: - n عدم وجود اتصال شخصي بين الدارس والمدرس. تستند المراسلة على برنامج مطبوع ومكاتبات بريدية. ويشتمل محتوى البرنامج في التعليم بالمراسلة على ما يلي: المقدمة.

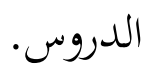
الأسئلة.

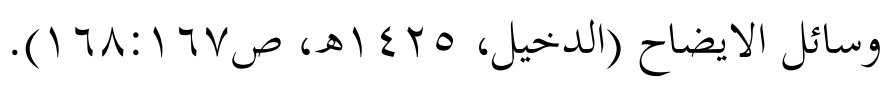

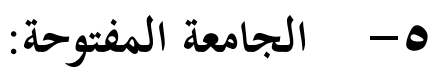

تأتي فكرة الجامعة المفتوحة مع انتشار الديمقراطية، وتعتمد على تكافؤ الفرص التعليمية، والتوسع في فرص التعليم الجامعي. وهو يعد نوعاً من التعليم المستمر، ولقد ظهرت الفكرة في اليابان عام با 9 ام حيث اطلق عليها جامعة بلا جدران، ثم انتشرت بالعالم وافتتحت بريطانيا عام 979 ام الجامعة المفتوحة.

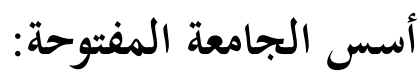
تعليم الكبار. تزايد التعليم الاذاعي. توسيع نطاق ديمقراطية التعليم.

مميزات الجامعة المفتوحة: يستخدم هذا النوع من التعليم لخدمة اعداد كبيرة من الطلاب. 
يحقق الاتصال بين المعلم والطالب مما يساعد على فهم المادة العلمية. يستفيد من هذا التعليم الطلاب الذين ليس لديهم القدرة على مواصلة التعليم التقليدي لظروف اقتصادية او جغرافية (الدخيل، 0بـ اهـ، ص • V ) ).

علاقة الامية بالثنمية: - م

لقد أعطى كثير من المربين تعليم الكبار قيمة عظيمة، فقد طالب (إيلتش، وفريري، وكارنوي، ونولز، وجنتر) بالقضاء على المدرسة، بل وعلى التعليم الإلزامي بصفة خاصة لأن المدرسة تقود دائماً إلى الانتحار الفكري.

فالأمية تعد جانباً من الفقر القابل لظروف معيشية هي دون النصاب في أغلبية شعوب العالم الثالث، ومما لاشك فيه أن الدافع الأساسي وراء إبراز الدور الممكن للتعليم في التنمية هو قصور الاستثمارات المادية عن تحقيق المعدلات المرغوبة للتنمية الشاملة. إن الاطار الاجتماعي والثقافي الذي تتفاعل في ظل السياسة الاقتصادية، والذي يتم في إطاره تنفيذ سياسات الإنماء الاقتصادي هو الأكثر فعالية في تحقيق المعدلات المرغوبة في النمو، وأن هذا الإطار يؤثر على تكوين إرادة التنمية بعناصرها الثلاث: ا ـ الوعي بمشكلة التخلف وأبعادها. r. الوعي بضرورة القضاء على ظاهرة التخلف. r. الوعي بأساليب وأدوات القضاء على ظاهرة التخلف. ومن المعروف أنه لا يمكن أن توجد تنمية في أي بلد إذا لم تستغل الموارد البشرية الاستغلال الأمثل، وهذا الاستغلال لا يمكن أن يكون إلا إذا كانت هذه الموارد على مستوى جيد من الناحية العلمية. فتنمية الموارد البشرية عملية ضرورية لتحريك وتنمية القدرات والكفاءات البشرية في جوانبها العلمية والعملية والسلوكية. فالأمية من اهم المعوقات التي تعترض كافة بحالات التنمية، فلا نتوقع لشعب من الشعوب ان ينطلق في أي بحال من بحالات التنمية وهو يرزخ تحت وطأة نسبة عالية من الأمية التي 
تشكل حاجزاً مظلماً يهول بين العقل وبين استقبال كل ما هو مفيد من معلومات لتطوير

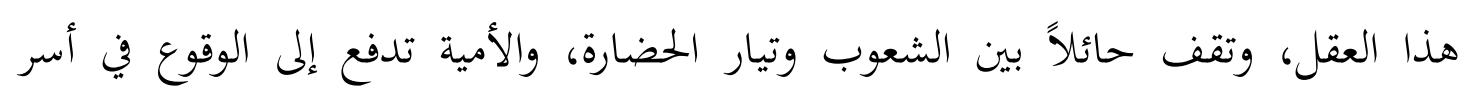

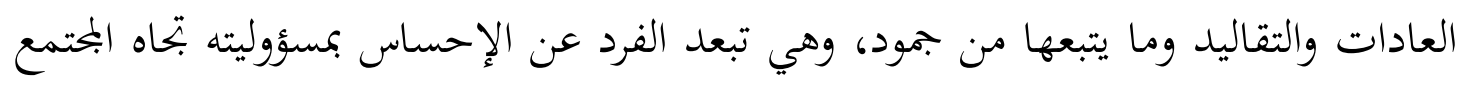

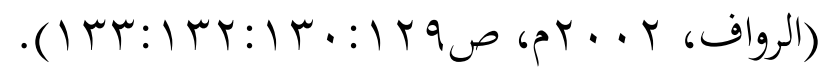

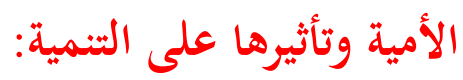
إن ارتفاع نسبة الأمية وانخفاض نسبة الالتحاق بالمدارس خاصة في أوساط الإناث يؤثر على

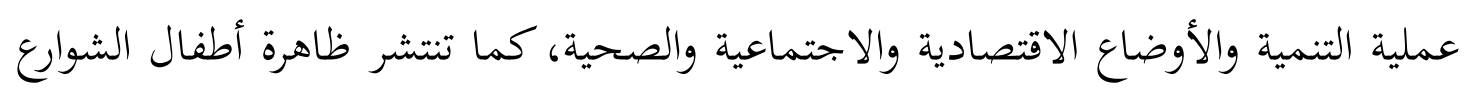
كظاهرة اجتماعية ازدادت في الآونة الأخيرة بسبب سوء الأوضاع الاقتصادية للأسر الفقيرة والمعدمة. مما تتسبب في ظهور عمالة الأطفال في الفئة العمرية (7-ـ اسنة)، وتبرز خطورة

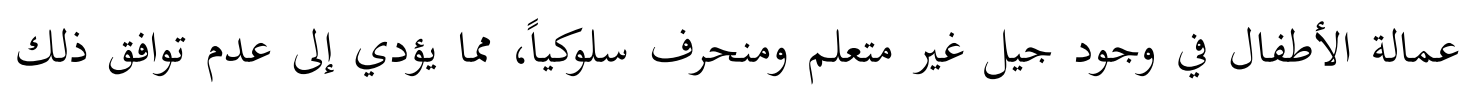

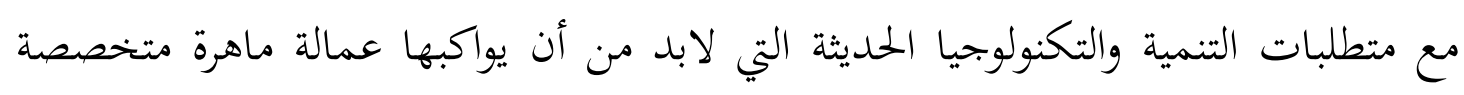
وذات كفاءة عالية، كما أن عمالة الأطفال تساعد على زيادة حجم البطالة وبالتالي أتساع

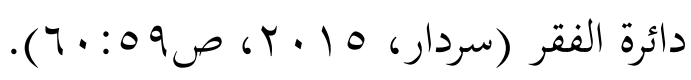


المحور الثاني: التنمية وعلاقتها بالثربية

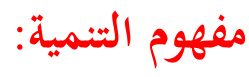

"عبارة عن عملية تحرر وفضة حضارية شاملة، تقتضي الانعتاق من شبكة علاقات السيطرة

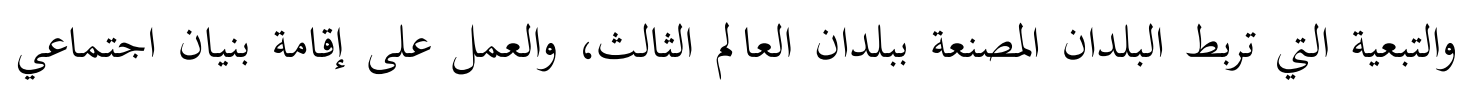
اقتصادي سياسي متوازن، يحمل في طياته بذور استمراره وتطوره باطراد" (بدران

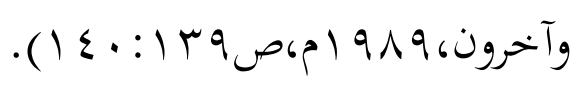

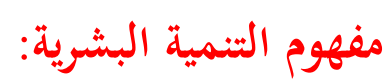
يقوم هذا المفهوم على أن "البشر هم الثروة الحقيقية للأمم" وأن التنمية الإنسانية هي عملية

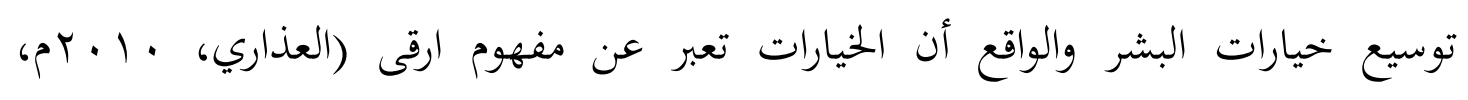
.(01)

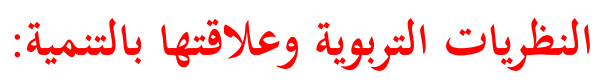
العلاقة بين التربية والتنمية علاقة حتمية تظهر في التأثيرات والتفاعلات المتبادلة بين خطط

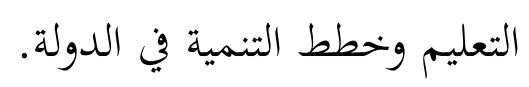

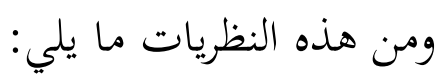

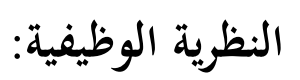

تعكس النظرية الوظيفية فكرة أهمية العمل وعلاقته بالإنتاج، وتحسين رأس المال البشري، بالتركيز على التأهيل والتدريب وعلى المهارات العليا للأداء والانتاج التي يجتاجها الاقتصاد

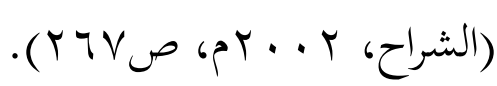

$$
\begin{aligned}
& \text { نظرية التشريع: }
\end{aligned}
$$

تعتمد على افكار عديدة من تلك التي وردت في النظريات السابقة لأفا بتمع كل العناصر

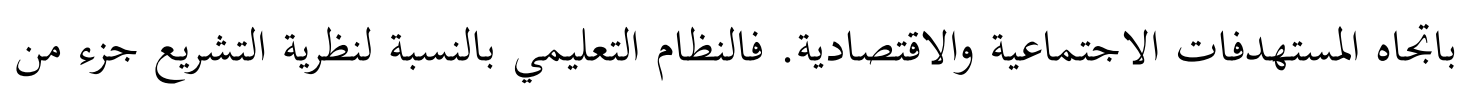
نظام كلي اجتماعي لا ينحصر دور الفرد فيه على ابتاه واحد وإنما على تحقيق تنمية شاملة 
تتطلب تفاعل كل العناصر في اطار شمولية الاهداف وتنوع الخيارات وتققيق الرغبات

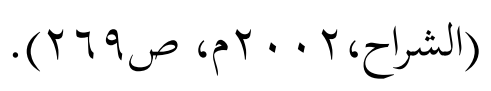

\section{النظرية التقدمية:}

تتركز النظرية التقدمية للتعليم على جعل الطالب مركز عملية التربية، من حيث أبعاده العقلية والسيكولوجية والاجتماعية، ولابد أن ينظر المى هذه الابعاد بشكل متوازن. فالطالب بقدر ما يحقق حاجاته المختلفة من التعليم، عليه أن يتعلم المهارات التي تنفعه وتفيد البحتمع

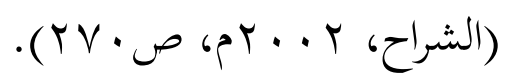

\section{نظرية مراحل النمو عند والت روستو:}

ظهرت في أواخر الستينات وترى أن التطور الاقتصادي والبشري يتم في شكل مراحل متتابعة سينتقل البمتمع فيه من مرحلة الى المرحلة التالية. وبذا تكون تنمية بلدان العالم الثالث ممكنة طالما أها تتمكن من استيعاب العوامل التي تنقلها من مرحلة الى المرحلة التي تليها، وهذه المراحل على النحو التالي: - - مرحلة المجتمع التقليدي. r - ب مرحلة التهيؤ للانطلاق. r- مرحلة الانطلاق الفعلي. ع - مرحلة الابحاه نهو النضج. - - مرحلة الاستهلاك الكبير.

ولقد وضعت نظرية مراحل النمو عند روستو معياراً نقيس به درجة تقدم المختمع، فالدولة التي تنطبق مظاهر حياتا الخاصة والعامة على أي من المرحلتين الأولى والثانية تعتبر دولة متخلفة، أما الدولة التي تضعها مظاهر حياتا في المرحلة الثالثة فهي في مركز الوسط ليست متخلفة تماماً ولا متقدمة تماماً إنما هي بين بين. أما التي تضعها مظاهر حياتما في المرحلة الرابعة أو 
المرحلة الخامسة فهي دولة متقدمة مع التفاوت في مستوى التقدم (بدران وآخرون، 919 (م)

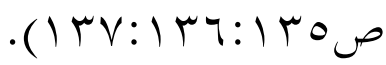

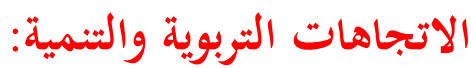

لقد فرضت الطبيعة التربوية عدداً من الاتحاهات العامة تلاحظ في معظم أنظمة التعليم، وخصوصاً الأنظمة المتقدمة، وكثر حولها النقاش ليس لكوها اتجاهات عامة مرغوبة تعكس مضامين سامية ولكن في مدى قدرة الأنظمة على التمسك بها بما تتمشى مع الأعراف والنظم والظروف القائمة لكل نظام تعليمي، ولأهيتها فإننا نشير إلى أهم هذه الاتحاهات: 1. إن التعليم حق إنساني بغض النظر عن الجنس والجنسية والدين واللغة والبيئة. r. قوة التعليم الذي يمتلك الإمكانات المادية والبشرية المتمثلة في الفلسفة والاهداف

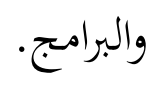

r. التعليم والنخبة وتعني العلاقة القائمة بين التعليم من جهة وبين النخبة الاجتماعية

$$
\text { والسياسية والاقتصادية من جهة اخرى. }
$$

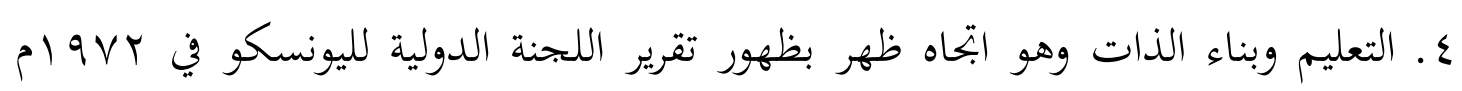

$$
\text { بعنوان " تعلم لتكون - عالم التربية اليوم وغداً ". }
$$

هـ التعليم للإبداع فقد أصبح العقل والابداع من أهم المكونات الانسانية الذي دلت عليه التجارب في بحال تنمية قدرات البحث والفضول والتجريب والانتاج الابداعي (الشراح،

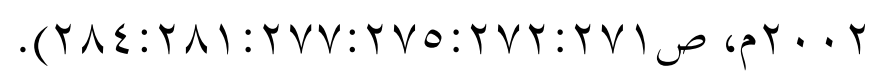


العلاقة بين العلم والتكنولوجيا وبين التنمية: إن البحث العلمي والتكنولوجي يخلق المتطلبات الضرورية لتحقيق وتطوير متطلبات التنمية، الأمر الذي يجعله من العوامل الرئيسية في عملية التطور الاقتصادي والاجتماعي، وتظهر آثار العلم والتكنولوجيا في التنمية بالأمور التالية: زيادة القدرة على استغلال الطاقات الإنتاجية الحالية للمشاريع.

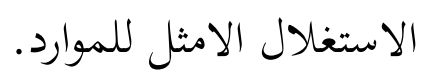

$$
\text { رفع معدلات الإنتاجية للقدرة البشرية. }
$$

ت تنمية الموارد الزراعية والمعدنية والطاقة لمواجهة التحديات بزيادة عدد السكان.

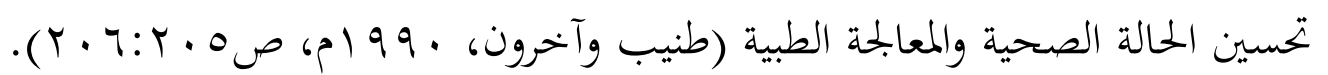

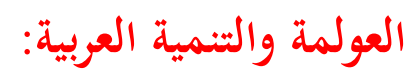

شهد الوطن العربي منذ أواخر الستينات نمواً متسارعاً في معدل انتقال العمالة من الوطن العربي إلى الخارج، ولكن أهم من ذلك بكثير هو التسارع في هجرة العمالة بين دولة عربية

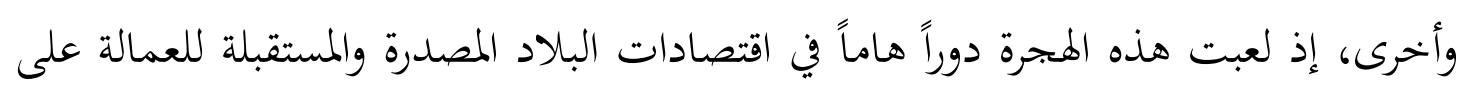

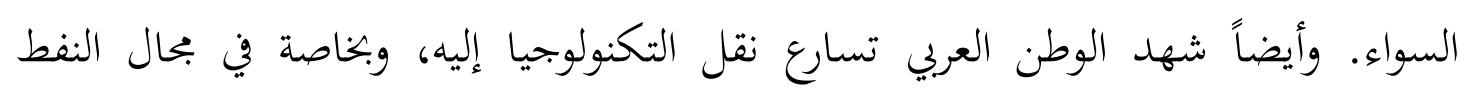
والسلاح والبتروكيماويات. ومع ذلك فإن الكثيرين يعبرون عن آمال واسعة في أن تزداد سرعة العولمة ودرجة الإندماج للإقتصادات العبية في الإقتصاد العلمي نتيجة الإتفاقات الجديدة (أمين، 999 (م) .$(\varepsilon \vee: \varepsilon \varepsilon ص$ 


\section{المحور الثالث: معوقات التنمية البشرية}

المعوقات هي كل ما يعطل التنمية الانسانية ويحد من حركتها ومساهمتها في التنمية العامة. فهناك جملة من المعوقات الخارجية ذات الصلة التأثيرية بالنظام التربوي، وذلك لصعوبة احتوائها ومعالجتها من القطاع التربوي. فهي معوقات ليست تحت سيطرة التربية لكنها تحتاج إلى جهود كبيرة وتنسيق هائل من أجل تجنب أثنارها وانعكاساتما على العملية التعليمية

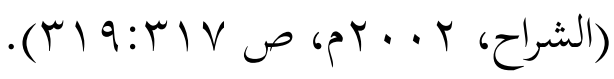

$$
\begin{aligned}
& \text { ومن المعوقات الخارجية ما يلي : } \\
& \text { 1- السكان : }
\end{aligned}
$$

يعتبر السكان أحد أبرز المسائل في بجال الدراسات الاقتصادية والاجتماعية والتربوية لما له من أثر بالغ على مختلف ميادين التنمية. ومن جانب آخر فإن الدراسات السكانية تبين حجم القلق الذي يسود الكثير من المجتمعات حول الاختلالات في أوضاعها السكانية، خاصة في الدول النامية التي تعاني غالبيتها من الانفجار السكاني في ظل الفقر والأمية والتخلف والمرض بين سكاها. وعلى الرغم من تفاوت درجة المشكلة السكانية بين الدول إلا أن الظاهرة السكانية المتفجرة بعامة تظل معضلة عالمية كبرى تتفاقم يوماً بعد يوم وتنذر بالمخاطر كلما اشتد البحث عن الغذاء، والمأوى، والصحة، والتعليم في ظل تواصل النمو

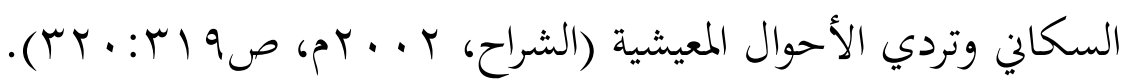

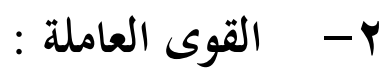

إن معظم المشكلات التي تعاني منها نظم التعليم في العالم تتعلق بعدم قدرها على إعداد الإنسان لمواجهة احتياجات سوق العمل، ومسايرة التبدلات الدائمة في هذه الإحتياجات. بحد دول كثيرة ما زالت تعاني من مشكلة البطالة بين المتعلمين نتيجة الزيادة العالية في أعداد الطلاب وما يترتب على ذلك من توسع في التعليم وتضخم في مخرجاته. 
وباستقراء الاحصاءات حول نسب البطالة في العالم لابد من التأكيد على أنه ليس هناك بحتمع لا يعاني من مشكلة تشغيل خريجيه، حتى الدول المتقدمة كاليابان والنرويج وامريكا

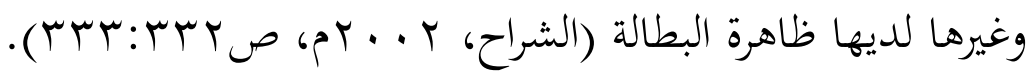

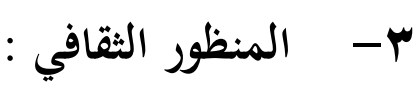
ترتبط الثقافة بالتنمية البشرية ارتباطاً وثيقاً. فكلما ازدهرت الثقافة ارتفعت معدلات التنمية البشرية، لذلك فالثقافة في أي بجتمع صفة دالة على التنمية. ولا توجد ثقافة بدون بحتمع، ولا يوجد بحتمع بدون ثقافة. ومن المعروف أن الثقافة لما استمراريتها ولا تتوقف عند مرحلة زمنية أو في بيئة جغرافية معينة، فالثقافة تستمر بعد موت الانسان وتنتقل من جيل لآخر لأن الثقافة لصيقة بكل فرد وبحتمع تميزه عن غيره.

لذلك فإن الثقافة العالمية في إطار العولمة ستجعل من الثقافات الأخرى غير القادرة على المسايرة عرضة للتفكك والانكماث أمام ما تقدمه الثقافة العالمية العولمية من لغة وقيم ومناهج

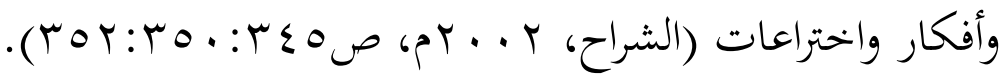

$$
\begin{aligned}
& \text { ع- - المنظور السياسي : }
\end{aligned}
$$

ترتبط التربية بالنظام السياسي كما ترتبط بالميادين الحياتية الأخرى، فما يحدث للنظام التربوي من اختلالات بجد صداها وانعكاساهما على النظام السياسي، والعكس صحيح، فأي خلل أو ارتباك في المنظومة السياسية للمجتمع له آثار سيئة على الأنظمة التربوية. إن الولاء والانتماء كلمتان مكملتان لبعضهما على الرغم من اختلاف المعنى والمضمون، فبينما الولاء يعني الروابط وتمسك الفرد بالجماعة والدولة بنح أن الانتماء تنحصر دلالته اللفظية في درجة الالتزام بالقيم والاعراف والنظم. إن الأمن السياسي مفهوم واسع يدخل فيه كل العناصر الداخلية في زعزعة الإستقرار، وكثيرون لا ينتبهون أن الأمن القومي مرتبط بعناصر الفقر والأمية، وعدم المساواة، والتطرف، 
وضياع الموارد الطبيعية، وانتشار القلق والعنف وأمور أخرى، مما يعني ارتباط الأمن السياسي

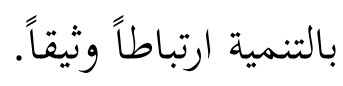

و في كثير من دول العالم الثالث نحد أن السياسة التعليمية تنصب على إبراز ايدلوجية النظام السياسي في المناهج الدراسية، ويتضح ذلك في مقررات الدراسات الاجتماعية والانسانية

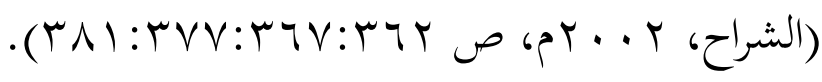

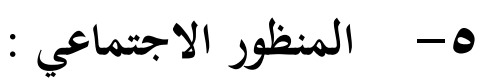

تساهم المدرسة في المحافظة على قيم الجُتمع وتقاليده وعاداته في إطار النقل الثقافي وقد أكد على هذا الكثير من علماء التربية والاجتماع. إن المدرسة بما تقدمه من معرفة ومهارات وقيم وغيرها مؤسسة تسعى للتغيير في سلوك الفرد

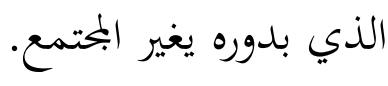

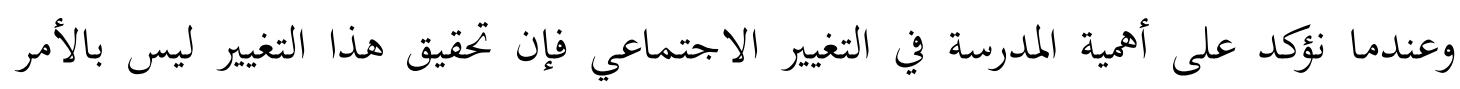
اليسير، فهناك عوامل اجتماعية واقتصادية وسياسية مؤثرة على دور المدرسة يجب أن تؤخذ

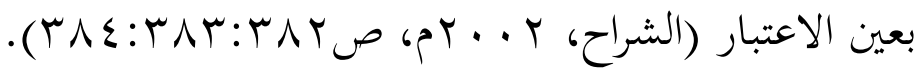

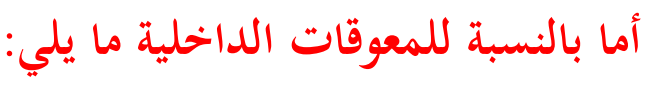

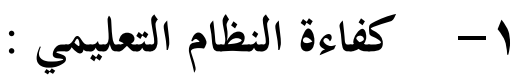

إن من أعظم مشاكل التنمية سببها تدني كفاءة التعليم، فالكفاءة العالية تُعد من أهم مؤشرات تطوير التنمية البشرية، فالكفاءة تعني القدرة على تحقيق الاهداف المنشودة

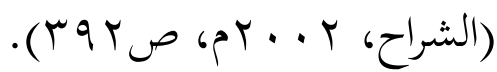

$$
\begin{aligned}
& \text { r- الإدارة التربوية : }
\end{aligned}
$$

تشكل الإدارتان التربوية والمدرسية عاملاً مهماً في التنمية البشرية، فالإدارة متوغلة في كل جانب من جوانب النظام التعليمي، في المدرسة وفي التخطيط وفي الإدارة العليا. لذلك فإن العملية التعليمية يستحيل أن تحدث بدون الإدارة، بل إن تحسين التعليم مرتبط بمدى قدرة 
النظام التعليمي على إستثمار المفاهيم والطرق الحديثة للإدارة التربوية (الشراح، ج ... Yم،

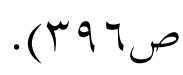

\section{ب- السياسة التعليمية :}

السياسة التعليمية لابد ان تكون جزء من سياسات الدولة في الميادين الإقتصادية والإجتماعية والسياسية باعتبار أن التربية علاقتها وثيقة ومترابطة بالتنمية وتستند على مبادئ الإنسجام والتكامل وليس على التناقض والاختلاف، فالسياسة التعليمية تتمثل في الرؤية

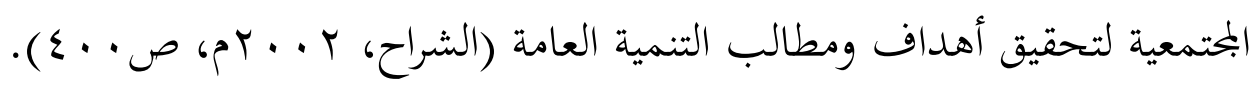
ع - مهنة التعليم : - مه يعتبر المعلم حجر الزاوية في العملية التعليمية، فهو مؤتمن على الأبناء، فالمعلم أمام هذه المهمة الجسيمة يواجه سيلاً من الانتقادات من الآباء والطلاب والمؤسسات الاجتماعية إذا حدثت مشكلة عن التعليم. ومهنة التعليم تتمحور حول الشروط التالية: أن يكون المعلم ملماً بمادته وتخصصه.

أن يكون لديه القدرة على استخدام التقنيات الحديثة ونظريات التعلم المختلفة. أن تكون شخصية المعلم حوارية غير متسلطة أو مستبدة.

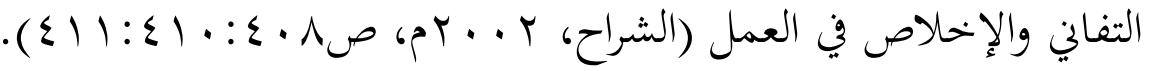

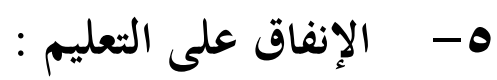

يستحيل تحقيق تنمية بشرية دون أن تتوافر الأموال اللازمة للإنفاق على التعليم، فالإنفاق على التعليم يتأثر بجملة من العوامل أبرزها حالة الميزانية العامة للدولة، فكثير من طموحات

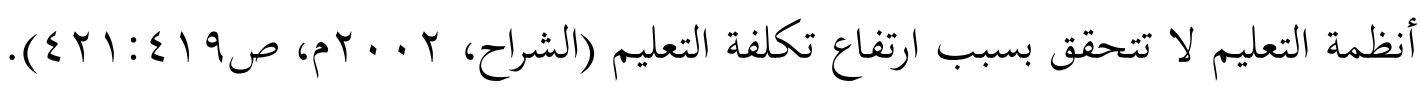




\section{المحور الرابع: الدراسات السابقة}

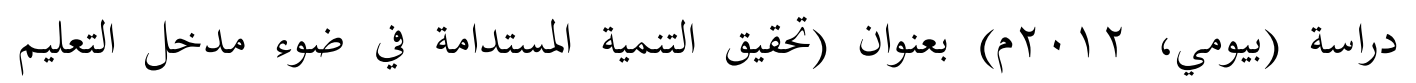
للجميع)، والتي هدفت إلى توثيق الصلة بين التعليم من أجل التنمية المستدامة ومبادرة التعليم للجميع، وقد استخدم الباحث المنهج الوصفي في دراسته.

ومن خلال الدراسة توصل الباحث إلى النتائج التالية: أن التنمية المستدامة هي أسلوب يجمع بين المسائل الأساسية في التنمية وبين حماية البيئة، من أجل التغلب على المشكلات البيئية، وهذا الأسلوب يمكن أن يضم العلاقات بين البيئة والتنمية. والتعليم من أجل التنمية المستدامة فرؤية التعليم تركز على الصلات بين الإنسان والمكان الذي يعيش فيه والموارد. دراسة (زيتون، با • r م) بعنوان ( إشكالية التنمية في مصر بين ميراث الليبرالية الجحديدة وتطلعات مجتمع المعرفة)، والتي هدفت إلى نشر ثقافة المعرفة، وتطوير مهنة التدريس والتعليم في ظل بحتمع المعرفة، وضمان جودة التعليم وتقييم نتائجه. وقد استخدم الباحث المنهج الوصفي في دراسته.

ومن خلال الدراسة توصل الباحث إلى النتائج التالية: حدث تطور ملحوظ في قطاع تكنولوجيا المعلومات والاتصال في مصر، ونتجت عنه بالضرورة منافع وإيجابيات للمصريين، سواء في تيسير الحصول على المعلومات ومشاركتها، وتسهيل الاتصال، أو تحسين الخدمات عامة. ويستنتج الباحث بالنهاية أن مصر ماتزال بعيدة عن بجتمع المعرفة، فلا بد من مواجهة التحديات التي تعيق التحول نحو بحتمع المعرفة. دراسة (الرافعي، r I • rم). بعنوان (دور تعليم الكبار في تحقيق التنمية المستدامة). والتي هدفت إلى أهداف تخطيطية تتعلق بالمحيط الحيوي وتتمثل في: صيانة الموارد الوراثية

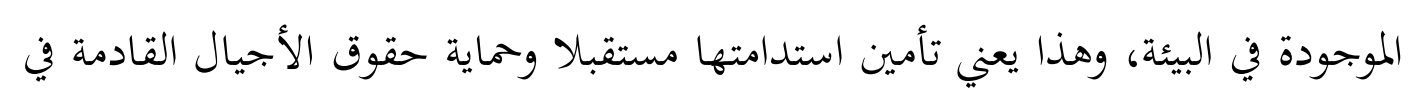
بيئة غير مستنزفة، للمحافظة على التوازن البيئي، وفي هذا تأمين واضح لحق الأجيال 
القادمة في بيئة آمنة. وهناك أهداف تخطيطية تتعلق بالتكنولوجيا المستخدمة بتشجيع

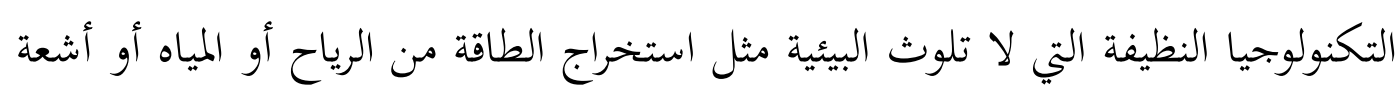

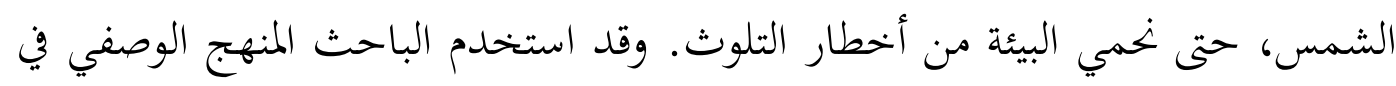
دراسته. ومن خلال الدراسة توصل الباحث إلى النتائج التالية: أن تؤخذ في الإعتبار التأثيرات الإقتصادية والإجتماعية والبيئية طويلة الأمد في جميع القرارات الخاصة بتنفيذ السياسة. وأن تحقيق التنمية المستدامة لا يتأتى إلا من خلال التعاون على المستوى الإقليمي والعالمي. 
المحور الخامس: نتائج البحث والتوصيات

توصل هذا البحث إلى النتائج التالية:

1- - ظهور نوع جديد من أنواع الأمية الحديثة يسمى بالأمية الإلكترونية، والتي تساهم في بناء القدرات وخاصة المرتبطة بتقنية المعلومات.

r- أن هناك أربع أبعاد رئيسية لمحو الأمية الإلكترونية، من أبرزها التصميم الإلكتووني للدروس الذي يهتم بالجانب العملي التطبيقي لهذه البرامج.

r- - أن هناك علاقة ارتباطية بين الأمية والتنمية، فالأمية تؤثر على عجلة التنمية بمختلف أبعادها، فهي من اهم المعوقات التي تعرض لها العديد من الباحثين، فالأمية تقف

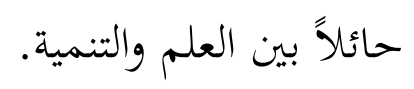

ع - إن العلاقة بين التربية والتنمية علاقة حتمية تظهر في التأثيرات المتبادلة بين خطط التعليم وخطط التنمية، في أي دولة من الدول ، وقد ظهرت العديد من النظريات التي توضح العلاقة بين التربية والتنمية من أشهرها (النظرية الوظيفية، والتشريع، والتقدمية، ومراحل النمو). ه- - إن من أهم الإتحاهات التربوية الحديثة في بحال التنمية ما يلي: إن التعليم حق إنساني بغض النظر عن الجنس والجنسية والدين واللغة والبيئة. قوة التعليم الذي يمتلك الإمكانات المادية والبشرية المتمثلة في الفلسفة والاهداف

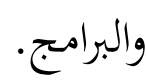
التعليم والنخبة وتعني العلاقة القائمة بين التعليم من جهة وبين النخبة الاجتماعية والسياسية والإقتصادية من جهة أخرى.

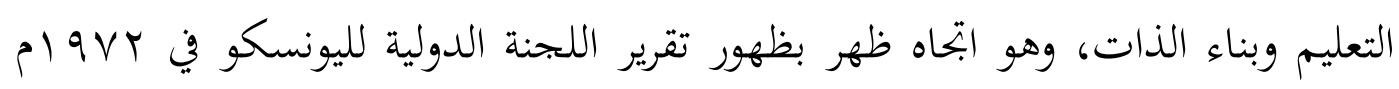
بعنوان (تعلم لتكون - عالم التربية وغداً). 
التعليم للإبداع، فقد أصبح العقل والابداع من أهم المكونات الإنسانية الذي دلت عليه

التجارب في بحال تنمية قدرات البحث والفضول والتجريب والإنتاج الإبداعي.

يوصي الباحث في هذا البحث بما يلي:

ا - - دراسة العلاقة التأثيرية بين الإقتصاد والتنمية الثقافية وأثرها على برامج محو الامية في الدول النامية.

r- اجراء دراسات مقارنة بين المؤثرات العالمية من حروب سياسية وأزمات اقتصادية، وتأثيرها على مكافحة الامية ونشر برامج التوعية الثقافية في العديد من البلدان. r- اجراء دراسة ميدانية في بحال تقصي علاقة الأمية بالتنمية الشاملة للمجتمع. 


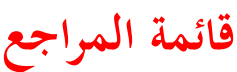

أمين، جلال. (999 1م). العولمة والتنمية العبية. بيروت: مركز دراسات الوحدة

العربية.

بدران، إبراهيم، والصقور، محمد، وخرابشة، عيد، وهندي، صالح. (919 (م). قضايا التنمية في الوطن العربي. عمّان: دار الفكر للنشر والتوزيع.

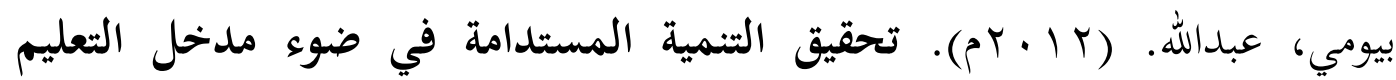
للجميع. تونس: بحلة تعليم الجماهير، سنة (9 ب)، العدد (99). الدخيل، محمد بن عبدالرممن. (Y0 أه). قراءات في محو الأمية وتعليم الكبار.

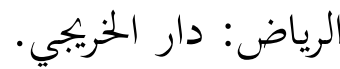

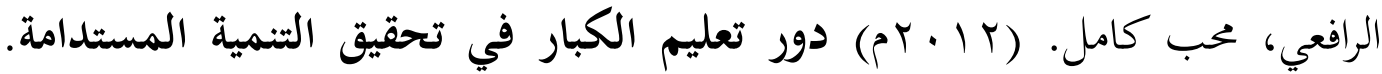
تونس: بحلة تعليم الجماهير، سنة (؟9)، عدد (09). الراوي، مسارع حسن. (9/VV ام). دراسات حول محو الأمية وتعليم الكبار في الوطن العربي. بيروت: المكتبة العصرية للطباعة والنشر. رشوان، حسين عبدالحميد أحمد. (ع ا ·ץ). الأمية الهجائية والوظيفية وتعليم الكبار. الإسكندرية: مركز الإسكندرية للكتاب.

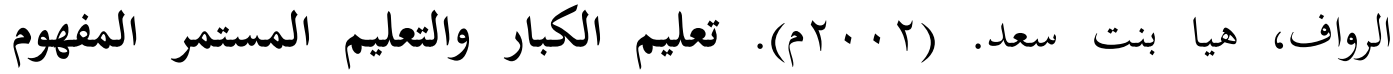
الخصائص النطبيقات. الرياض: مكتب التربية العربي لدول الخليج.

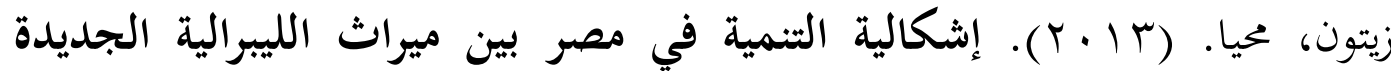
وتطلعات مجتمع المعرفة. مصر: البجلة المصرية للتنمية والتخطيط، عدد (1). سردار، عبدالرممن سيف. (0 ( ب م). اقتصاد الفقر وتوزيع الدخل. عمّان: دار الراية ل النشر والتوزيع. 
الشراح، يعقوب أمد. (ץ ․ ץم). التربية وأزمة التنمية البشرية. الرياض: مكتب التربية العربي لدول الخليج. طنيب، محمد شفيق، وبدران، أمية فارس، وسلمان، مصطفى حسين، ومحمد، حسين ياسين. (.991/). أبعاد التنمية في الوطن العببي. عمّان: دار المستقبل للنشر والتوزيع. الطيطي، صالخ حسين. (9/1 (م). مشكلات الوطن العربي ودور التنمية الشاملة في مواجهتها. عمّان: مديرية المكتبات والوثائق الوطنية.

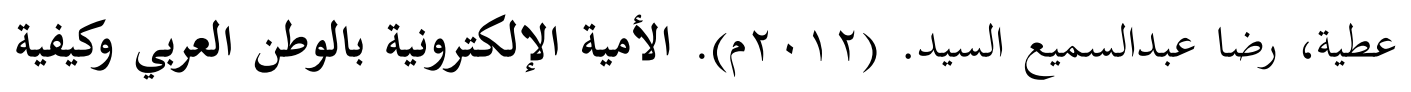
علاجها. الإسكندرية: دار الجامعة الجديدة. العذاري، عدنان داود، والدعمي، هدى وزير . (· · ץم). قياس مؤشرات ظاهرة الفقر في الوطن العربي. عمّان: دار جرير للنشر والتوزيع. 